\title{
Política Industrial E Competitividade: de Collor a FHC
}

Oswaldo Guerra *

\section{INTRODUÇÃO}

$1 \begin{aligned} & \text { té o final da década de } 70 \text {, a política industrial brasileira esteve } \\ & \text { subordinada ao modelo de substituiçāo de importaçōes, no } \\ & \text { qual priorizava-se a reduçāo do coeficiente de importaçōes e a ex- }\end{aligned}$ pansāo da capacidade produtiva. Estas metas eram perseguidas, basicamente, através da imposiçāo de barreiras tarifárias e nāo-tarifárias e da concessāo de incentivos e subsídios, visando a redução do custo do investimento e, eventualmente, do custo de produçāo. Se ela foi exitosa em termos de garantir uma convergência com o padrão industrial e tecnológico internacional até entāo vigente, o mesmo não pode ser dito quanto à sua capacidade de tornar a ampla e diversificada base industrial construída, eficiente, competitiva e adaptada às novas tecnologias utilizadas a partir dos anos 80 (Guimarães, 1995).

A rigor, como bem demonstram Suzigan \& Villela (1997:43), a política industrial brasileira, até o final da década de 70 , acumulou diversos problemas, podendo-se destacar:

$\rightarrow$ o protecionismo excessivo, nāo-seletivo, sem metas de phasing-out e sem a exigência de contrapartidas de desempenho por parte das firmas como, por exemplo, exportaçōes e desenvolvimento tecnológico;

$\rightarrow$ o quase desleixo em relação à capacitação tecnológica; e

$\rightarrow$ a forte intervenção regulatória sobre preços, salários e investimentos, gerando reservas informais de mercado em alguns setores ou indústrias, 
eliminação de competiçāo em preços e queda ou estagnação de salários reais, que não se beneficiavam de ganhos de produtividade.

Assim sendo, era necessário mudar não apenas para corrigir tais problemas, mas também porque havia se esgotado um processo histórico de desenvolvimento. $\mathrm{Na}$ década de 80 , mais precisamente a partir de sua segunda metade, algumas modificaçōes começaram a ser feitas, com o intuito de simplificar o aparato legal e institucional e, de certo modo, diminuir as restriçōes existentes. Todavia, tais modificaçōes não significaram um afastamento radical do padrão anterior. Isto só iria ocorrer com a Nova Política Industrial e de Comércio Exterior (PICE), definida no início do Governo Collor. A prioridade deslocou-se da expansāo da capacidade produtiva e da substituição de importaçōes, para o estímulo à competição e a busca da competitividade como objetivo empresarial básico (Guimarāes, 1995).

O objetivo deste texto é justamente o de reconstituir essa ruptura na prática da política industrial no Brasil, iniciada em 1990, e seus desdobramentos até o primeiro semestre de 1997. Tais desdobramentos, ao longo destes sete anos, compreendem momentos de total rejeição à política industrial, na linha da célebre frase do ex-presidente Reagan, para o qual "a meIhor política industrial era nāo ter política industrial", até o renovado interesse recente pela mesma, motivado pela explicitaçāo do trade-off déficit corrente $\mathrm{x}$ crescimento econômico, trazido à cena pela maneira como tem sido conduzido o Plano Real.

O presente artigo compreende, além desta introduçāo e da conclusāo, três partes. Na primeira, busca-se precisar os termos política industrial e competitividade. A seguir, avalia-se a PICE introduzida pelo Governo Collor e que permanece, praticamente sem alteração, no período Itamar Franco. Por fim, examina-se o processo de profundas transformaçōes que vem sofrendo a indústria brasileira, intensificado a partir de 1995, e as tentativas recentes de se adotar novas diretrizes de política industrial, adaptadas ao atual cenário nacional e internacional. 


\section{Definindo Política Industrial e \\ COMPETITIVIDADE}

Apoiado em autores como Adams \& Bollino (1983), Johnson (1984) e Corden (1980), Suzigan \& Villela (1997) consideram a política industrial num sentido amplo, como uma expressão abrangente de programas e medidas que afetam direta ou indiretamente o setor industrial. Nesta perspectiva, ela envolveria os seguintes elementos: planejamento geral indicativo; formalizaçāo de objetivos e diretrizes; organizaçāo institucional específica; articulação com a política macroeconômica; adoção de medidas de fomento direcionadas para setores industriais especificos (industrial targeting policy); investimento em infra-estrutura econômica e de ciência e tecnologia; e apoio ao sistema educacional, ao treinamento de mão-de-obra e à formação de recursos humanos especializados. Além disso, ela contemplaria também instrumentos e políticas auxiliares (políticas de comércio exterior, políticas regionais e políticas de regulação e competição).

Para um outro grupo de autores Chang (1994), Itoh et al. (1991) e Krugman (1993), a política industrial deve ser definida num sentido mais restrito. Suzigan \& Villela (1997:16-17) tratam de precisar esta segunda visāo um pouco mais. Para Chang, o conceito de política industrial nāo pode ser sobrecarregado, sendo nele incluído tudo que seja bom para o desenvolvimento industrial. Ela é algo dirigido para indústrias específicas e as firmas que a compōem, buscando resultados que são vistos pelo Estado como eficientes para o conjunto da economia. Os argumentos de Itoh et al. vão na mesma direção. A política industrial afeta o bem-estar econômico de um país ao intervir na alocaçāo de recursos entre indústrias ou na organizaçāo industrial de indústrias específicas. Krugman, por sua vez, considera que a política industrial deve se restringir a identificar setores industriais localizados geograficamente (geographical clusters) e apoiar suas vantagens competitivas, de modo a criar externalidades positivas para o conjunto da economia. Segundo Suzigan \& Villela (1997:17), esse approach poderia ser simbolizado da seguinte maneira: "olhe o mapa, identifique concentraçōes industriais e apoie indústrias que geram economias externas", visāo esta que assemelha-se bastante com a defendida por Porter (1990). 
Para ambos os grupos de autores, as medidas de política industrial podem ser de natureza vertical (industrial targeting policy), isto é, direcionadas para específicos setores industriais, tecnologias ou produtos, ou de caráter horizontal, que se destinam a melhorar as condiçōes industrias de um modo geral ${ }^{1}$. Todavia, pode-se dizer que para o segundo grupo de autores, políticas verticais não sāo desejáveis por interferirem diretamente no mecanismo de mercado, escolherem setores industriais para serem beneficados, além de terem o poder de favorecer o surgimento de atividades e/ou empresas puramente rentistas. Por isso, elas devem ser preteridas em favor de medidas horizontais, que não privilegiam setores industriais, mas propiciam ganhos de produtividade para a indústria como um todo, viabilizando elevação nos salários reais e na acumulaçāo de capital, sem pressionar os preços, garantindo assim um incremento no bem-estar econômico geral.

Essas medidas horizontais de natureza específica, definidas no âmbito da política industrial, não devem ser confundidas com as açōes horizontais de natureza geral, que tratam de transformar a educação, o sistema tributário, a infra-estrutura econômica e social etc. Os que negam qualquer tipo de política industrial, por distorcer os sinais de mercado, sugerem que a intervençāo estatal seja limitada a açōes dessa natureza. Ao gerarem efeitos positivos, elas tornam o ambiente econômico mais propício para todas as atividades produtivas (primárias, secundárias e terciárias) e nāo apenas para a indústria.

Se o objetivo último da política industrial for o de incrementar a produtividade e a competitividade, entendida como a capacidade das empresas formularem estratégias que lhes permitam manter e/ou ampliar de forma sustentada sua posição no mercado $^{2}$, políticas verticais e horizontais (de natureza geral e específica) se sobrepōem. Afinal, a empresa é o veículo da:competitividade, mas a construção de vantagens competitivas nāo depende apenas de variáveis controladas pelas firmas (determinantes internos). Tal construçāo é igualmente influenciada por fatores associados à estrutura de mercado na qual elas se inserem e por condicionantes sistêmicos, que são impactados pelas açōes horizontais de natureza geral, a pouco mencionadas. Por tudo isto, é que o enfoque aqui assumido, para efeito de se avaliar a interrelação entre política industrial e competitividade, a partir do Governo Collor, será o de política industrial lato sensu. 


\section{A Política Industrial do Período COLlOR/ITAMAR Franco ${ }^{3}$}

Em seu desenho original, a PICE, divulgada em 26 de junho de 1990, compreendia duas linhas de açāo. Uma política de competitividade, destinada a apoiar as empresas em seus esforços para aumentar a eficiência e induzi-las a promoverem transformaçōes, consonantes com as características da terceira revoluçāo industrial e tecnológica; e uma política de concorrência , fundada em dois pilares: abertura comercial e incentivo à competição doméstica e desestímulo a práticas monopolistas. Explicitamente, a PICE assume a tarefa de implementar "formas de atuação governamental e de regulação da atividade econômica substancialmente diferentes daquelas vigentes ao longo do processo de substituição de importaçôes". Para tal, indica ser "necessário utilizar de forma mais eficaz as forças de mercado para induzir a modernização tecnológica do parque industrial e para aperfeiçoar as formas de organização da produção e da gestão do trabalho" (Guimarães, 1995:5).

Nesse novo contexto, o movimento inicial da PICE foi o de desmontar o sistema de proteção e incentivos, que vigorou ao longo das décadas anteriores, através de várias medidas. Vale destacar, o cronograma de redução tarifária que deveria se estender até 1994, mas foi antecipado para 1993. A tarifa aduaneira média foi reduzida de $32,2 \%$ em 1990 para $14,2 \%$ em julho de 1993, enquanto que a tarifa modal caiu, no mesmo período, de $40 \%$ para $20 \%$. Ainda na linha da abertura, foi redefinido - para efeito de concessão de benefícios fiscais, financiamentos por entidades oficiais de crédito e compras governamentais - o conceito de bens de capital de fabricação nacional, admitindo-se índices de nacionalizaçāo de $70 \%$ e, posteriormente, de 60\% (Guimarāes, 1995:9). Além disso, após o impeachment do presidente Collor, no contexto do gerenciamento do plano Real, o Governo Itamar Franco antecipou para outubro de 1994 a implementação da Tarifa Externa Comum (TEC), negociada no âmbito do Mercosul, cuja vigência estava prevista para janeiro de 1995. 
Do ponto de vista restrito da sua implementação, a política de abertura pode ser considerada exitosa, pelo simples fato dela ter sido conduzida sem contramarchas, algo bem distinto da tentativa anterior feita em 1988, no Governo Sarney. Existia um receio que a liberalização não fosse efetivada ou se iniciada fosse revertida, dado os interesses dos setores que se beneficiavam da estrutura anterior. Para Guimarāes, o sucesso na remoçāo das barreiras tarifárias e nāo-tarifárias apoiou-se:

$\rightarrow$ na onda liberalizante que marcou o mundo no início dos anos 90 , particularmente a derrocada do leste europeu e as experiências de abertura comercial da América Latina;

$\rightarrow$ no singular quadro político do início do Governo Collor, governo esse que nāo representava interesse de nenhum segmento político relevante; $\mathrm{e}$

$\rightarrow$ na desorganizaçāo que se seguiu à mal conduzida reforma administrativa do Governo Collor, responsável pela desarticulaçāo de possíveis grupos de resistência dentro da burocracia federal.

Quanto aos resultados alcançados, uma avaliação mais precisa será feita na próxima seção, inclusive porque os impactos de uma redução tarifária ocorrem com uma certa defasagem, além dos mesmos terem sido magnificados pela valorização do real. Neste ponto, importa destacar o seguinte aspecto: a abertura teve o mérito de tornar a busca da competitividade, uma prática corrente das empresas.

A nova política industrial proposta, nāo se resumia, todavia, à política de abertura. $\mathrm{Na}$ implementaçāo do incentivo à competição doméstica $\mathrm{e}$ desestímulo a práticas monopolistas, segundo pilar da política de concorrência, e na política de competitividade os avanços foram modestos. Como bem aponta Guimarāes (1995:24), os avanços são modestos pois o aumento da concorrência no mercado interno e os ganhos de competitividade do sistema produtivo foram induzidos pela abertura e alcançados a partir dos esforços realizados pelas empresas, e nāo por estímulos ou apoio propiciados pela PICE. A política de competitividade, o incentivo à competiçāo doméstica e a restrição a práticas monopolistas exigem ação articulada e continuada do setor público, algo bem distinto da abertura, que implica exatamente na limitação da intervençāo do Estado.

No caso específico da política de competitividade - embora tenham sido implementados o Programa Brasileiro de Qualidade e Produtividade (PBQP) e, de certo modo, o Programa de Apoio a Capacitaçāo Tecnológica 
da Indústria (PACTI) -, ela sequer chegou a ser formulada. Isto decorreu das dificuldades enfrentadas no âmbito do Estado para definir e operar uma nova agenda de política industrial. No que tange às políticas horizontais de caráter geral, os obstáculos localizam-se na dura tarefa de reunir condiçōes políticas e financeiras para o Estado reduzir as chamadas fragilidades competitivas sistêmicas (as questōes educacional, portuária, tributária, energética etc.). Quanto às de natureza específica (promoção da qualidade e produtividade, apoio à capacitaçāo tecnológica industrial, promoçāo às exportaçōes industriais, legislaçāo anti-dumping etc.), as limitaçōes maiores associam-se as dificuldades de operar novos instrumentos, a carência de marco legal e do quadro institucional, adequados às características da nova política, e ao despreparo das agências governamentais envolvidas.

Finalmente, resta considerar as políticas verticais. Diferentemente das políticas horizontais, os obstáculos não se limitaram a dificuldades de implementação, de reunir condiçōes políticas e/ou financeiras ou a problemas operacionais. Como sublinha Guimarāes (1995:35), "as dificuldades estāo associadas a sua própria formulação - vale dizer, a definição mais concreta de seus objetivos e ao desenho e à articulação dos investimentos e mecanismos a serem mobilizados". Considerando o atual contexto nacional e internacional, os objetivos a serem perseguidos por uma política industrial vertical sāo distintos da época da substituição de importaçōes. A experiência internacional sugere que se busque: a promoção de indústrias estratégicas, especialmente aquelas que apresentam intenso ritmo de progresso técnico e são difusoras de tecnologia e geradoras de externalidades; e a reestruturaçāo industrial, de modo a induzir transformações que incrementam a competitividade.

No que diz respeito ao primeiro objetivo, até o final do Governo Itamar Franco, o fracasso da política de informática parece ter inibido novas tentativas. Quanto ao segundo, tudo indica que o fato de algumas empresas terem "espontaneamente" respondido à abertura, tornando-se mais competitivas, induziu a uma avaliaçāo errônea: o país poderia prescindir de uma política de reestruturação industrial. Negava-se a política industrial vertical e delegava-se ao mercado a tarefa de livremente estimular o ajuste. 


\section{A Política Industrial do GOVERNO FHC}

Mesmo antes da posse do Governo FHC, existiam evidências da limitaçāo do processo de ajuste a alguns setores e de que os efeitos do processo de abertura sobre o parque fabril brasileiro nāo tinham ainda se esgotado, devido aos seguintes motivos: num primeiro momento, o fluxo de importaçōes responde lentamente às reduçōes tarifárias, em razão da inexistência de canais adequados de comercialização; prevaleceu um quadro recessivo no início da década, reduzindo a atratividade do mercado interno; e a abertura iria se aprofundar com a aplicação definitiva da TEC, a ampliaçāo do Mercosul e a valorização cambial que deveria ser sustentada.

Apesar da confirmação deste quadro, permanecia como principal desafio de política industrial, a formulação e implementação de uma industrial targeting policy voltada para os dois objetivos a pouco mencionados. O Governo FHC manteve-se, inicialmente, efetivamente imobilizado. Parecia predominar a crença de que "a melhor política era uma não-política, decorrente de ideologias e/ou do medo legítimo de um retrocesso com relação à abertura da economia e da volta às velhas políticas de subsídio, que tanto contribuíram para o déficit público" (Barros \& Goldstein, 1997). Enquanto isso, intensificava-se o processo de profundas transformaçōes produtivas, organizacionais e patrimoniais pelo qual vinha passando a indústria brasileira.

Diante de uma conjuntura macroeconômica que tem combinado, pelo menos até o primeiro semestre de 1997, baixo crescimento, déficits comerciais, juros internos elevados, abertura comercial e valorização cambial, as empresas têm tido diversas reaçōes. Algumas reduziram o escopo de suas atividades industriais concentrando-se em alguns segmentos e completando suas linhas de produtos com importaçōes. Outras recorreram à importação de máquinas, insumos e equipamentos, o que possibilitou ganhos de produtividade. Vários grupos postergaram planos de expansão, desmobilizaram ativos nāo estratégicos, principalmente aqueles caracterizados como especulativos, e reduziram o grau de diversificação de suas estruturas. Por 
fim, certas empresas, como última alternativa, optaram por paralisar, sucatear ou vender unidades industriais menos eficientes ou com elevada capacidade ociosa. Adicionalmente, e isto é válido para quase todos, recorreram à terceirização de diversas atividades e compactaram os processos produtivos, através de cortes substanciais de postos de trabalho e programas de reestruturação (Ferraz \& Coutinho, 1994).

De um modo geral, o processo de globalização, a abertura e a valorizaçāo cambial expuseram duramente a estrutura produtiva nacional, resultando, para Coutinho (1996), em desindustrializaçāo parcial, aliada à concentraçāo de capitais e à desnacionalização da produção doméstica, inviabilizando até mesmo empresas competitivas do ponto de vista técnico e gerencial. Para ele, a desindustrializaçào avança em três frentes:

$\rightarrow$ redução do valor agregado no país em todas as cadeias industriais complexas, onde parte crescente da produção dos componentes, peças e matérias-primas é substituída por importados. Na cadeia automobilística, por exemplo, o índice de nacionalização dos produtos cai velozmente, já estando em $85 \%$ a caminho de $60 \%$. No setor eletroeletrônico, o peso dos insumos importados subiu para mais de $50 \%$;

$\rightarrow$ perda de produção doméstica de bens finais pela ocupação do mercado por produtos importados. Parcela crescente da oferta de têxteis, vestuário, calçados, eletrodomésticos leves, alimentos industrializados, máquinas e equipamentos estaria sendo suprida por importaçōes;

$\rightarrow$ finalmente, em muitos casos, a produção doméstica foi suprimida (várias especialidades na área química/petroquímica, componentes e bens de capital).

A desindustrialização só nāo teria atingido os nossos setores competitivos de grande escala ( $1 / 3$ da indústria) baseados em recursos naturais e energéticos - papel/celulose, alumínio, siderurgia, processamento mineral. Mas, neste caso, a rentabilidade das exportaçōes vem sendo onerada pelo câmbio valorizado. A combinação juros, câmbio e avalanche de importações - que no periodo 1993-95 saltaram de US $\$ 25,2$ bilhōes para US $\$ 49,7$ bilhöes - vem comprimindo as margens de lucro, desestruturando empresas competentes e provocando desnacionalização, como foi o caso da Metal Leve.

Alguns empresários, como Paulo Villares e Paulo Cunha, respectivamente dos grupos Villares e Ultra, concordam com essa posição e consideram que a abertura foi rápida e pouco planejada. Alguns números: o coefi- 
ciente das importaçōes, excluindo petróleo, no PIB da indústria de transformaçāo saltou de 13,1\% em 1989 para 34,4\% em 1996 (GZM, 1997a). O próprio ministro da Indústria do Comércio e do Turismo (MICT), Francisco Dornelles, reconhece que os ajustes tarifários feitos no país no passado recente, "não levaram em conta a situaçāo dos diversos segmentos da indústria. A conseqüência dessa medida é que morreram inocentes e culpados" (GZM, 1997b).

Adicionalmente, constata-se um desempenho extremamente desigual entre os setores industriais: aumentos das vendas e da produção - fortemente concentrados em bens de consumo duráveis (40\% entre 1994 e 1996), com destaque para autos, eletrônicos e eletrodomésticos, e nāo-duráveis ( $9,5 \%$ no mesmo período), principalmente alimentos, bebidas e higiene e limpeza, estimulados pela estabilidade de preços e expansāo do crédito -; investimentos para modernização e ampliação da capacidade localizados, em boa parte, nesses mesmos setores; fusōes e aquisiçōes; e déficits comerciais crescentes. Já a performance de outros setores sugere crescente fragilização produtiva e financeira e/ou retração de atividades (bens de capital, fabricantes de matérias-primas, insumos e componentes: eletrônicos, autopeças, têxteis e farmacêuticos (Laplane \& Sarti, 1997:3).

Esse desempenho desigual seria uma conseqüência do processo de especialização industrial (importação crescente de peças e componentes pelos produtores de bens finais) iniciado com a abertura e acentuado a partir do segundo semestre de 1994, em funçāo do câmbio e da disponibilidade de financiamento externo para importaçōes. Laplane \& Sarti reconhecem que a especializaçāo traz como contrapartida aumentos da rentabilidade e dos níveis de competitividade, representados por ganhos de produtividade e reduçōes de custos operacionais e financeiros. Todavia, fazendo coro com a argumentação de Coutinho, alertam para o fato de que em termos sistêmicos, ela implica em fragilizaçāo dos encadeamentos produtivos e tecnológicos, perda do poder multiplicador da indústria e, sobretudo, impactos negativos no balanço comercial.

Em agosto de 1996, após mais de um ano de entrevistas com empresários, consultores econômicos, pesquisadores universitários e debates com os gerentes setoriais do BNDES, José Roberto Mendonça de Barros (Secretário de Política Econômica do Ministério da Fazenda) e Lídia Goldstein (Assessora da presidenncia do BNDES) tornaram público, através de um trabalho publicado na Gazeta Mercantil, algumas hipóteses sobre o que estaria 
ocorrendo com a indústria brasileira. Para eles, o país não estaria se desindustrializando, muito pelo contrário, passava por um profundo processo de reestruturaçāo industrial, mesmo considerando que importaçōes de todos os tipos invadiam fábricas, lojas e camelôs e grande número de indústrias fechava suas portas.

A globalização, a abertura, a estabilização e as privatizaçōes estariam recriando os determinantes do investimento nacional e internacional, exigindo um novo olhar dos analistas para compreendê-los. A invasão das importaçōes não seria uma ameaça, mas uma procura das empresas aqui instaladas para reduzir custos e enfrentar a concorrência que, pela primeira vez, sofriam. De outro lado, o crescimento das importaçōes resultaria do interesse que o mercado brasileiro, um dos mais atraentes do mundo, estaria despertando nas empresas internacionais em funçāo da estabilização e abertura.

Em ambos os casos, as importaçōes teriam impactos mais positivos e profundos que a mera substituiçāo da produçāo local. Além de viabilizarem a sobrevivência de produtores locais, via redução de custos e modernização, as importaçōes seriam o primeiro passo no processo de vinda de novas empresas. Primeiro, elas importam produtos para testarem o mercado e criar redes de distribuidores. Sentindo receptividade, instalam fábricas. Até este momento, crescem as importações de componentes e de máquinas e equipamentos para as novas plantas industriais. Posteriormente, começariam os impactos positivos sobre o balanço comercial. Cessariam as importaçōes de máquinas e equipamentos e optaria-se pelo fornecimento local, pois ele barateia custos de transportes, agiliza as relaçōes com o mercado e viabiliza o just-in-time, fazendo o outsourcing perder sentido. Deste modo, setores que num primeiro momento são externalizados, aos poucos são internalizados novamente. A indústria automobilística é tomada como ilustração deste movimento.

Essa argumentação governamental não convence críticos como Laplane \& Sarti (1997), particularmente no que diz respeito à tese de que o fluxo de importaçōes de bens de capital representa a criação futura de capacidade produtiva e competitividade, dando condiçōes para que crescimento industrial e equilíbrio externo se compatibilizem. Antes de expressar qualquer sentimento otimista, é essencial identificar quais os setores que estão ampliando ou modernizando seu parque fabril e examinar seu potencial exportador. Para tal, eles apoiam-se em duas pesquisas. 
Numa primeira, realizada pelo NEIT/UNICAMP junto a 80 grandes empresas estrangeiras industriais, quantificou-se US $\$ 15$ bilhōes de investimentos realizados e previstos, entre 1994-98, metade dos quais localizados no complexo automobilístico, envolvendo 31 empresas, e $25 \%$ direcionados para os setores eletrônico, de eletrodomésticos e higiene e limpeza. Ou seja, os investimentos estão fortemente concentrados nos setores de consumo e voltados ao mercado interno, não havendo pois evidências que sustentem a expectativa de que os atuais investimentos das empresas estrangeiras sejam capazes de equacionar crescimento e equilíbrio externo.

Para Laplane \& Sarti, as empresas estrangeiras continuam privilegiando o mercado doméstico e/ou o Mercosul. A estratégia é utilizar em menor grau a base produtiva local como plataforma de exportação para o restante da América Latina ou para as economias avançadas. Essas conclusões seriam confirmadas por uma outra pesquisa realizada pela CNI e CEPAL junto a 730 empresas industriais. Segundo tal pesquisa, as empresas prevêem centrar investimentos nos setores de consumo voltados para o mercado interno e projetam aumentos simultâneos nos coeficientes de importaçāo e exportação, sem que seja possível estabelecer uma tendência de reversão dos déficits comerciais.

Além disso, Coutinho rebate os argumentos do governo de que a maioria das importaçōes seja de bens de capital, o que resultaria, mais adiante, em reestruturação industrial e, consequentemente, em aumentos das exportaçōes. No período de 1994 a 1996, a compra de bens de capital importados aumentou $13,9 \%$, a de bens de consumo $35,2 \%$ e a de matériasprimas e produtos intermediários $34,9 \%$ (GZM, 1997a). Ou seja, as importações estariam crescendo de forma generalizada.

Voltando ao governo, a mesma pesquisa feita pela CNI/CEPAL é utilizada por Barros \& Goldstein (1997), para destacar que as empresas estāo passando de uma primeira fase de investimentos em redução de custos e aumentos de produtividade, para uma segunda fase de ampliação de capacidade instalada. Mas, o importante a ser destacado no artigo desses dois economistas, é o reconhecimento de que isto por si só não basta. Dada a heterogeneidade dos diversos setores produtivos, eles defendem uma política de investimentos e competitividade, para que o processo de reintegração produtiva, localizado basicamente na automobilística e em outros segmentos finais, se consolide e se espraie para os demais setores industriais. Para isso, o governo tem estudado as necessidades de cada se- 
tor industrial (automóveis, têxtil, calçados, autopeças, bens de capital, entre outros) e desenvolvido políticas verticais, elevando inclusive, em alguns casos, as alíquotas de importação.

Adicionalmente, foi encomendado um estudo à Associaçāo de Comércio Exterior do Brasil, concluído no primeiro semestre de 1997, no qual identificou-se o que mais se compra no comércio internacional e quem fabrica. Vale mencionar alguns dados apresentados no mesmo. Dos 33 grupos de produtos cuja demanda mais cresceu no mercado mundial, entre 1980 e 1994, o Brasil só está presente no setor automotivo. Todavia, sua taxa média anual de crescimento $(9,2 \%)$ está entre as quatro últimas. Entre os produtos líderes estão as unidades digitais centrais de memória, os equipamentos para processamento de dados e os microcircuitos eletrônicos. A idéia do governo é ir atrás das empresas produtoras e convencê-las a investir no Brasil, para que o país diversifique sua inserção no mercado internacional, hoje apoiada basicamente em produtos abundantes em mão-de-obra e recursos naturais e energéticos. Esta diversificação é crucial, pois, no mesmo período (1980-1994), o comércio mundial de soja cresceu apenas $2,7 \%$ ao ano e para importar um pentium multimidia, o Brasil precisa atualmente vender 200 toneladas de minério de ferro, 30 toneladas de soja ou 4 toneladas de carne de frango (GZM, 1997c).

Quanto às políticas horizontais gerais, vários passos têm sido dados na área da educação, tributaçāo, portos, ferrovias, estradas etc. Nas políticas horizontais especificas, de suporte às exportaçōes de manufaturas, por exemplo, avançou-se na desoneração fiscal e na criaçāo do seguro de crédito e de linhas especiais. As autoridades governamentais admitem a necessidade de um avanço maior e reconhecem o atraso na organização dos canais de comercializaçāo e na reestruturaçāo do sistema financeiro brasileiro, de modo a viabilizar recursos para o financiamento industrial de longo prazo. 


\section{CONCLUSÕES}

Renova-se, pois, o interesse na política industrial. $\mathrm{O}$ governo $\mathrm{FHC}$ rompeu com o imobilismo e decidiu-se a fazer política industrial lato sensu (horizontal e vertical), ainda que o gerenciamento do Plano Real crie incompatibilidades entre as políticas macroeconômica e industrial, como os elevados níveis das taxas reais de juros. Não é nada que se assemelhe a um Plano de Metas ou a um II PND, pois como visto os tempos sāo outros, mas já se admite publicamente tal objetivo, considerado uma heresia até pouco tempo atrás. Esse redirecionamento, provocado em boa parte pelo agravamento das contas externas, é marcado pela maior influência que José Roberto Mendonça de Barros passou a exercer junto a FHC. Como se verá logo abaixo, ele é apontado pelo próprio presidente, como o formulador das novas idéias da política econômica, deslocando, assim, o Diretor de Assuntos Internacionais do Banco Central, Gustavo Franco.

Mendonça de Barros faz questāo de caracterizar a nova etapa "como de reconstrução institucional - marcada pela criaçāo de novos instrumentos de sustentação da economia". Para ele, existem duas grandes reestruturaçōes a serem feitas no país: uma do Estado e outra do setor produtivo, que está mais lenta do que o governo gostaria. "O problema não é só a chamada vontade política, temos que construir instituições, como, por exemplo, política industrial (grifo nosso). Sabemos que temos de construí-la, mas quais instrumentos devemos usar, que sejam adequados à situaçāo de hoje? Como fazer isso com o Mercosul e com a Organizaçāo Mundial do Comércio (OMC)? É mais fácil dizer que é preciso criar uma política industrial, como alguns colegas mais à esquerda fazem, do que dizer o que eles fariam hoje" (GZM, 1997c). O governo, segundo Mendonça de Barros, está fazendo uma aposta, baseado numa percepção de riscos, e não numa questão de fé, que tal estratégia de construçāo de instituiçōes e instrumentos, ajustados às novas realidades, evitará uma desindustrialização e garantirá uma reintegração produtiva, com redução de custos, alta de investimentos e compatibilizaçāo entre crescimento industrial e equilíbrio externo.

Nas palavras do presidente Fernando Henrique: "Você sabe que, em política como em economia, sempre se faz alguma aposta porque a política é 
o reino do imprevsível. Nāo é isso? Política não é a administração. A administração aplica regras e resolve, como no direito. Política é o oposto a isso. É o desafio. Sempre se faz alguma aposta. Qual é a nossa aposta? E quem mais formulou essa aposta foi o secretário de Política Econômica do Ministério da Fazenda, José Roberto Mendonça de Barros. Qual é a nossa aposta? É que nós estamos em uma fase em que estamos mudando o padrão estrutural do nosso sistema produtivo. Que, nesta fase, precisamos importar muito equipamento e matéria-prima. Que isso nos vai dar melhores condiçōes de competição internacional. Estamos nessa aposta. E vamos fazer isso. E esperamos que leve três a quatro anos. $E$ que, neste período, mesmo que haja déficit, como há déficit na balança comercial, há condiçōes de existir um clima de desenvolvimento e estabilidade política, e a capacidade de atrair capitais para financiar o déficit" (GZM, 1997d).

$\mathrm{Na}$ mesma entrevista à Gazeta Mercantil, o presidente detalha um pouco mais o teor da aposta e emite sua opinião sobre a abertura da economia. "De acordo com as medidas que estamos tomando, dentro desse processo de reestruturação em que estamos apostando, a preocupação é fazer com que ele não seja um processo de desnacionalização. A abertura da economia nāo foi feita por Gustavo Franco e nem por mim. Ela começou com Collor e foi acelerada por Itamar. Aí há uma parte que é minha como ministro da Fazenda: nós baixamos as alíquotas para uma média de 14\%. Havia muita pressão de São Paulo em cima de mim para não fazer isso. Eu concordei que deveria fazer porque achava que interromper o processo de abertura seria interromper efetivamente a nossa chance de modificar o sistema produtivo. Depois o processo foi acelerado no período do ministro Ciro Gomes, após os acordos feitos no encontro de Ouro Preto, quando baixamos muito as tarifas. Não foi o Gustavo quem fez. Ele estava em outra área: a área do câmbio. Ele apresentou a justificativa. Acho que explicou, com razão, que esta era a condiçāo necessária para este choque de capitalismo. Senão, teríamos aqui uma indústria protegida com câmbio favorável aos exportadores e o povo sofrendo".

Ele prossegue: "isto não quer dizer que o governo tenha que se despreocupar com o setor que vai sofrer com as conseqüências dessa abertura. Se nós fossemos então cuidar desses setores, nós não faríamos a abertura". Para o presidente, agora sim seria o momento de olhar com mais atenção para esses setores. Ao ser questionado pelos entrevistadores, se teria sentido ou seria importante, intervir setorialmente com o objetivo de, em 
grande parte, proteger a indústria nacional e impedir a desnacionalizaçāo, ele responde da seguinte maneira: "é importante porque os Estados Unidos fazem isso. A França e a Alemanha também. Isso tem a ver com a possibilidade de garantir as variáveis essenciais ao crescimento econômico. Em um mundo globalizado, se você não tiver algumas variáveis sob controle, você pode ter problemas muito sérios". E arremata: "eu nāo acredito que se deva deixar simplesmente as forças de mercado atuando".

Em suma, a retórica governamental aponta claramente para uma disposição de praticar política industrial lato sensu. Teria chegado a hora. Afinal, o processo de reestruturação da indústria brasileira - estimulado pela combinaçāo de rápida abertura e valorização cambial, e tendo como guia a mão invisível do mercado - realizou-se aos trancos e barrancos, foi agudo e violento, altamente concentrador e desnacionalizador, gerando os atuais problemas nas transaçōes correntes do balanço de pagamentos do país. A dúvida que permanece é se essa intervenção, destinada a reverter tal reestruturação desarticulada, nāo chega tarde demais. $O$ governo aposta que não. Façam as suas.

\section{Notas}

* Doutor em Economia. Professor dos Cursos de Mestrado em Administraçāo e Economia da UFBA.

E-mail: oguerra@ufba.br

${ }^{1}$ Apoio a atividades de $P \& D$ nas indústrias, incentivos ao estreitamento de relaçōes entre empresas industriais e universidades, regulaçāo de mecanismos de transferência de tecnologia industrial, apoio ao financiamento industrial etc.

${ }^{2}$ Ver a respeito Ferraz, Kupfer e Haguenauer (1995).

${ }^{3}$ A descriçāo feita a seguir, apoia-se fortemente em Guimarães (1995). 


\section{Bibliografia}

ADAMS, F. G. \& BOLLINO, A. (1983). "Meaning of Industrial Policy". In: KLEIN, L.R. Industrial Policies for Growth and Competitiviness. Lexington, Mass.: Lexington Books.

BARROS, J. R. M. \& GOLDSTEIN, L. (1996). "O processo de reestruturaçāo da indústria”. In: Gazeta Mercantil, 12/98/96.

(1997). "Como avan-

çar na política de investimento". In: Gazeta Mercantil, 07/04/97.

CHANG, H. A. J. (1994). The Political Economy of Industrial Policy. New York: St. Martin Press.

CORDEN, W. M. (1980). "Relationships Between Macroeconomic and Industrial Policies. The World Economy, v.3, n.2, p. 167-84, september.

COUTINHO, L. G. \& FERRAZ, J. C. (Coord.) (1994). Estudo de Competitividade da Industria Brasileira. Campinas: Papirus/ Ed. UNICAMP.

COUTINHO, L. G. (1996). "Desindustrializaçāo Escancarada". In: Folha de São Paulo, 20/10/96.

FERRAZ, J. C.; KUPFER, D. \& HAGUENAUER, L. (1995). Made in Brazil:Desafios Competitivos para a Indústria. Rio de Janeiro: Campus. GUIMARÃES, E. A. (1995). A Experiência Recente de Politica Industrial no Brasil: Uma Avaliaçäo. Rio de Janeiro: IEI/UFRJ (Texto para Discussão, n. 326).

GAZETA MERCANTIL (GZM, 1997a). "Empresários propōem reestruturação industrial". São Paulo, 21/05/97.

dos". São Paulo, 21/05/97.

(GZM, 1997b). "Morreram inocentes e culpa(GZM, 1997c). "Nova política cambial nem pensar". Sāo Paulo, 30/06/97.

(GZM, 1997d). "Abertura permitiu o choque de capitalismo". Sāo Paulo, 19/06/97.

ITOH, M.; KYONO, K.; OKUNO-FUGIWARA, M. \& SUKUMURA, K. (1991). Economic Analysis of Industrial Policy. San Diego: Academic Press. 
JOHNSON, C. (Ed.) (1984). The Industrial Policy Debate. San Francisco: ICS Press.

KRUGMAN, P. (1993). "The Current Case for Industrial Policy". In: SALVATORE, D. (Ed.). Protecionism and World Welfare. Cambridge: Cambridge University Press, cap. 7.

LAPLANE, M. F. \& SARTI, F. (1997). "Transformaçōes na Indústria, Inserção Internacional e Crescimento do Brasil". Indicadores IESP. Sāo Paulo: FUNDAP/IESP, n. 58, jan/fev.

PORTER, M. (1990). Vantagem Competitiva das Naçōes. Rio de Janeiro: Campus

SUZIGAN, W. \& VILLELA, A. V. (1997). Industrial Policy in Brazil. Campinas: UNICAMP/IE. 